Original Research Paper

\title{
Framework of Public Agency Website Quality Evaluation in the UAE
}

\author{
Mohammed Ali Albalushi, Zanariah Jano and Indra Devi \\ Innovation and Sustainable Technical Education Research Group, Universiti Teknikal Malaysia Melaka, Malaysia
}

\author{
Article history \\ Received: 24-09-2020 \\ Revised: 23-12-2020 \\ Accepted: 24-12-2020 \\ Corresponding Author: \\ Mohammed Ali Albalushi \\ Innovation and Sustainable \\ Technical Education Research \\ Group, Universiti Teknikal \\ Malaysia Melaka, Malaysia \\ Email: mamalbalushi@hotmail.com
}

\begin{abstract}
Website quality is among the key drivers of the success of egovernment transformation as citizens are more likely to participate when they found a satisfying engagement with a website. This paper proposed a framework of public agency website quality evaluation for the National Media Council, UAE. The study used a quantitative approach where a survey strategy was used to administer questionnaires to users of an agency's website. A total of 185 questionnaires were analysed using Partial Least Squares Structural Equation Modelling software (SmartPLS version 3.2.6). The result revealed that website quality had a statistically significant effect on user satisfaction. Similarly, it was further found that website quality had a statistically significant effect on perceived service quality. The result implies that users of NMC website interpret the quality of the agency's website from the purview of the satisfaction they derive from visiting the website and the perceived quality of the service offered through browsing the website.
\end{abstract}

Keywords: Perceived Service Quality, Public Agency, UAE, User Satisfaction, Website Quality

\section{Introduction}

The ever-changing innovation in the digital media technology alongside the rapid changes it has brought about in almost all spheres of human life have raised concerns over the truth, integrity and security of the users of the content provided by such media (WEF, 2016). Digital media has been described as products such as digital platforms (websites and applications), digitized content (e.g., text, audio, video and images) and services (e.g., information, entertainment and communication) that can be accessed and consumed through different digital devices (WEF, 2016). According to (Vaknin, 2009) digital media content encompasses digitized information and creative digital products such as e-books, e-journals, e-newspaper, digitized music, online digital games, videos, digital animations and others (Kim and Kim, 2017). These products and services are mostly access through the websites of the providers be it private or public organisations. Unlike the off-line media contents the issue of users or consumers' trust in the digital media content arises because of the difficulty in validating the truthfulness and veracity of the content (Hasan and Abuelrub, 2011). This scenario emanates from the fact that innovations in the digital media have removed barriers to content creation in such a way that almost everyone can create and publish content with little or no censure.

Digital media has brought about flexibility with respect to access to information on virtually every imaginable area of interest; yet, the vastness of such information makes it almost impractical to control. This limitation has raised concern about the quality of the contents found in the digital media (Hasan and Abuelrub, 2011). For instance, (Hargittai, 2007) lamented that the increase in the volume of content is associated with the rise in the amount of incorrect information on the online platforms which, in turn, presents a challenge in evaluating the credibility of online content.

Although various studies that examine different topics on the issue related to content quality which is a key dimension of online quality have been conducted, there is still a need to further investigate this phenomenon (Aladwani, 2017). This is especially true when consideration is given to the fact that the majority of the recent studies focus on the development of instruments that could be used in measuring website quality in an exploratory manner (Hasan and Abuelrub, 2011). A common characteristic of these studies is the recommendation to refine the content quality 
dimensions by means of testing the developed instruments (Aladwani, 2017).

Even though there is a considerable number of studies covering various subjects pertaining to social media platforms such as user relationships and user behavior (Aral et al., 2013; Aral and Walke, 2011; Chen and Teng, 2013; Jin, 2013; Khalil, 2017; Ryan, 2010; Zhao, 2016), societal, organizational and group management issues in social media platforms (Phang et al., 2013; Strother et al., 2009; Wu, 2013), social media technological issues such as system design, application design (Boldi et al., 2011; Hearst, 2011; Hasel, 2011; Kim and Kim, 2017; Sakaki et al., 2012; Stanujkic et al., 2018), information collection and analysis (Asadi and Lin, 2013; Crandall and Snavely, 2012) and other related topics, recommended the need for more research in the area of content quality of digital media platform especially within organizations. Among the studies on the subject, only (Awamleh and Fernandez, 2005) conduct their studies in the UAE despite the importance of the country in terms of the global internet use. For instance, (ITU, 2016) reported that $93 \%$ of the population of the UAE have access to the internet while it was ranked 11th position globally among the favourable environments for ICT (WEF, 2016). In addition, the UAE showed the highest mobile phone penetration rate in the Middle East region (187\%) and was ranked 35th globally in the UN ICT 2016 Development Index Freedo Home, 2017. Thus, the current research is expected to fill the identified gaps.

In addition, (Aladwani, 2017) analyzed both the theoretical and practical perspectives and found website content quality has become an important area that requires further investigations. This is evident from the substantial and growing number of research studies on the issue (Aladwani, 2013; 2014; Aladwani and Palvia, 2002; Dang et al., 2014; DeLone and McLean, 2003). However, an in-depth review of these studies revealed that the measurements of website content quality adopted are too technically oriented and non-situational. Therefore, the dimensions of website quality adopted in this study include: Navigation, e-service, aesthetic, transparency, site credibility, connectedness and interaction. In this context, navigation describes the interface of the website. It deals with how the menus, control panels and icons are arranged on the website pages in such a way that it allows users to easily interact with the interface (Díaz et al., 2017). Navigation helps website users to find the location of the information or service they visit the site for (Zaman, 2010).

E-service is defined as the provision of information, good or service to users of website. E-service include, downloading, uploading, submission, remote access, consultation and other activities provided on the website (Zaman, 2010). Aesthetic as a dimension of website quality means the overall outlook of the interface which include both visual and auditory characteristics of the websites such as colours, font, layout and others (Ritonummi, 2020).

Transparency refers to clear purpose, mission and identity of a website which does not confuse users. In the context of public sector website, it refers to those aspect of the websites that can allow users to gain trust in government or its agency (Verkijika and Wet, 2018). This implies that a website must provide a valid and relevant content for appropriate support information. On the other hand, site credibility connotes trust in the website. It concerns with building confidence in the users of the website and measured by the link popularity, visitor count, positive reviews and recommendation (Ritonummi, 2020; Zaman, 2010).

Connectedness means the degree of websites visitors' engagement through mutual interaction with the website. It is the emotional relationship between the website users and the website (Maulana and Cai, 2011). The extent of how website user is connected with the website explains the degree of attachment and loyalty to keep visiting and recommend the use of the website to others. Interaction is defined as the degree at which website users easily communicate with the e-service provider through the support tools provided on the websites. These tools include, chat bots, e-mail, social media handles and discussion forums (Brewer et al., 2006).

Furthermore, the majority of these studies disregard the potential existence of some other dimensions of the concept such as behaviour by focusing only on unidimensional conceptualisation and measurement of website content quality (Aladwani, 2017). To bridge the gap in theoretical realms, it is worthwhile to investigate other behavioural dimensions of measuring website content quality. This is especially necessary in the context of public sector websites where very little research pertaining to the websites quality is conducted.

Thus, this study was to investigate the issue of digital media content quality specifically focussing on the website quality of the National Media Council, UAE with a view to propose a framework that would help in ensuring that the content provided on the Council's website meet the quality criteria desired by users.

\section{Literature Review and Conceptual Framework}

Loiacono et al. (2002) developed the WebQual instrument for consumer evaluation of websites based on the theories of planned behaviour and Technology Acceptance model. The authors used instrument development process proffered by (Bagozzi, 1980; Bagozzi and Phillips, 1982) which involves defining the dimensions, developing the items, refining the items, confirming the validity and testing the framework using Structural Equation Modelling (SEM). The authors have successfully validated a reliable instrument for evaluating 
websites. Even though the study has successfully produced the WebQual instrument, the instrument may not be directly applicable to the public sector organisations or institutions. It is designed to evaluate website quality in e-commerce environment where competition exist among rival businesses with customers often have switching options whereas in the public sector setting, the website users may not have such options as the service provider usually acts as a monopolistic entity. Hence, this could limit the application of the instrument in evaluating public sector website, thereby enhancing the need for a more appropriate measures for evaluating public sector websites.

Bai et al. (2008) investigated the influence of functionality/usability of website quality and customer satisfaction on purchase intentions using a quantitative approach. It was found that the flow of information and nature of the content directly influence sales whereas quality of a website positively affects customer satisfaction, leading toward increased purchase intention. Extending these findings to the public sector website, it can be argued that high quality website may likely affect the level of users' satisfaction; however, website quality may be influenced by, not only functionality, but also other important dimensions as asserted by (Zaidi, 2017). Therefore, to include other dimensions of website quality is expected to improve the measures for website quality evaluation.

Mebrate (2010) designed an improved website quality evaluation framework for academic websites from students' perspective. The study involved a comprehensive review of website quality evaluation and usability literature, survey through questionnaires and checklist to identify, measure and evaluate the quality of the TU-Delft University website using the proposed framework. Some of the findings from the study revealed that the new proposed framework has a better construct of quality factors and sub factors as compared to the ISO 9126-1 evaluation model. In addition, the website, in general, has a good quality of reliability and efficiency characteristics, when simultaneously possess a moderate quality in its content, usability and functionality features. The study is conducted on universities as a facet of public institutions rather than the e-commerce setting, where the mode of operation of university and other public institutions such as the NMC in this case slightly varies. The website evaluation model successfully applied in the university setting may not appropriately capture the scene in such government agencies which provide a form of monopolistic service, hence, enhancing the need to investigate website quality issue from different perspective in this context.

Zaman (2010) tested a model for measuring quality of Public Sector Websites (PSW) and its influence on citizens' intention to be involved in the governing process by adopting a quasi-experimental research design using 159 participants. The result showed that the quality of PSW is critical to citizen's satisfaction whereas citizen's satisfaction mediates the relationship between disconfirmation and intention to be involved, internal and external political efficiency. Besides, the author found that regardless of the citizens' expectation of PSW, actual performance has a significant influence on their wishes to be involved. This study has provided a good model for evaluating website quality of public institutions. It provides a foundation for the present work where dimensions of website quality were adapted.

Abdallah and Jaleel (2015) developed an assessment tool and evaluation framework of e-marketing websites. The paper adopts a hybrid approach to website assessment which involves studying both information system elements and dimensions of e-marketing to define and measure the concept of web appeal. The model provides some systematic criteria for comparing websites and offers valuable insights into how website attributes can be used to achieve a desired performance in terms of attracting, engaging and retaining customers, as well as competing with rival stores. An important critique of the study is that its focus solely on ecommerce websites. The dimensions used in measuring website quality are restricted to the e-commerce environment rather than global measures. Thus, this limits the application of the developed tool in measuring website quality of public websites.

Chang et al. (2014) analyzed the influence of website quality and perceived trust on customer purchase intention. Data were collected using webbased survey and analysed using SEM. The findings yielded that website brand increases hotel purchases and orders, in that there is a strong connection between website quality and perceived trust for users who perceived superior website brand. In addition, a strong relationship between perceived trust and purchase intention due to the moderator of high service value is found. Aside being focused on business environment, the study does not emphasise on the role of website user satisfaction and service quality.

Qadar et al. (2016) conducted a study that evaluates the e-tax portal of Pakistan on the basis of the opinion of its users. Using explanatory and descriptive research by adopting triangulation research strategy, the authors analysed a sample of 300 registered tax payers in Lahore region from FBR Pakistan web portal. The t-test and EFA yielded that website's overall quality has a strong dependence on its system quality and information quality. A major problems faced by the users of e-tax portal are the poor loading as system takes too much time to load pages and often fails to proceed with the given command, especially on the peak days of filing returns. In addition, the majority of people are reluctant 
to file their returns by themselves just because this eportal is not quite user friendly. Thus, they bear heavy costs for consultancy matters. The most recurring error mentioned by users is the 'login error' where the system often does not recognize user ID or the password. System is not timely up-dated and users are not timely informed about any tax related update through the website. Although the study is conducted to evaluate public sector website, it does not emphasise the role of website user satisfaction and service quality which the current study seeks to investigate.

Jiang et al. (2016) conducted a study to investigate the determinants and impact of aesthetics in users' first interaction with websites. The study surveyed ten websites to validate the entire structural model. The results confirmed that perceived quality of the five design elements are indeed influential on users' perceived aesthetics; they have also shown that perceived aesthetics of a website has a significant impact on users' perception of its utility.

Ahmad et al. (2016) empirically analyzed the critical factors that determine perceptions of the service quality of online shopping sites by using a 25-item eTailQ scale instrument developed by (Wolfinbarger and Gilly, 2003) based on a five-point Likert scale to obtain the perception of a sample of students enrolled in a government-funded central university of India offering post-doctoral programs for undergraduates. The data were analysed using t-test, reliability analysis and EFA. The results indicated that Web layout, web info, customer service, fulfilment and privacy emerged as the critical factors affecting website service quality. This study highlights the most important dimensions that define website quality in the context of educational institutions. However, their relation to the concept of user satisfaction is not covered.

Weber and Badenhorst-Weiss (2018) analysed whether the quality of online grocery retailers' websites in emerging economies enhances or inhibits the growth of online grocery retailing. Based on the content analysis of the websites of nine (9) online groceries from BRICS countries by using two (2) prominent online grocer's websites from the United Kingdom as benchmark., it was found that websites of online grocers in BRICS countries comply with the quality criteria and are comparable (in terms of quality) with the websites of leading online grocers from the UK. The study evaluates website quality using benchmarked standards rather than through survey of websites users. Notwithstanding the fact that this may give insight into the quality of website, the quality of website measured using such criteria may not portray the actual user needs because the website used as the benchmark may not provide the expected utility to users. Therefore, it is worthwhile to capture the opinion of website users to ascertain the various aspect of the website that satisfy their needs.
Stanujkic et al. (2018) developed a new MultipleCriteria Decision-Making (MCDM) model based on the Weighted Sum Preferred Levels of Performances (WSPLP) for selecting alternatives and Pivot Pairwise Relative Criteria Importance Assessment (PIPRECIA) method for determining weights of the evaluation criteria. Using Numerical analysis of multi-criteria decision-making model, the findings yielded that usability and efficiency are numerical examples of website evaluation for the hotels in Timok region (Eastern Serbia). Although a novel mathematical approach is used to evaluate website quality, a well organised survey of actual website users to understand their feelings and opinions about the different facets of the website could give a more realistic evaluation, hence, enhancing the need to investigate the website quality from user satisfaction and service quality frameworks.

\section{Conceptual Framework}

The theoretical underpinning of this study is based on the Herzberg's Two-Factor Theory. The choice of the Herzberg's Two-Factor Theory is induced by the fact that the quality of public websites needs to focus on how network quality affects citizens' e-government adoption and user satisfaction. This is necessary because public sector websites largely monopolize most of the information and services offered. In this way, it is noteworthy to speculate on how and to what extent the quality of the site affects user satisfaction. The Herzberg's Two-Factor Theory is regarded as an instrumental theory in understanding user satisfaction in management and business environment. The theory was extended to study user satisfaction with website and internet related environment with earlier works in this area pioneered by (Zhang et al., 2000; Zhang and Von Dran, 2000; Mueller and Mack, 2003).

The Herzberg theory was originally used in the management field where consumer behaviour was investigated. Herzberg (1968) theorized that there are two factors of motivation that guide consumer and/or worker behaviour. These factors can be distinguished as dissatisfiers (factors that cause dissatisfaction) and satisfiers (factors that cause satisfaction) which Herzberg termed as hygiene factors and motivators respectively (Mueller and Mack, 2003). In a work place setting where the theory was first developed, attempts were made to test those variables which can be manipulated to increase job satisfaction. It was observed that if dissatisfiers are not eliminated, then workers will not be motivated. However, (Mueller and Mack, 2003) stated that even with the elimination of the dissatisfiers, satisfaction cannot be achieved unless it is derived from the work itself. According to (Zhang et al., 2000) the dissatisfiers describe extrinsic factors that impact a person's relationship on the environment or context where he or she operates. 
In the context of work environment, these factors could be salary, company policy and administration, interpersonal relations and supervision. The presence of these factors in work place removes dissatisfaction, however, they do not cause people to be highly satisfied or motivated in their work. Rather, satisfaction is derived from a group of intrinsic factors, the satisfiers. These factors describe a person's relation to what he or she does. The factors could be the job content, achievement of task, responsibility for task and professional advancement or growth in task capability (Zhang et al., 2000).

Applying this theory in the website context, a typical task user of website is involved in accessing and retrieving information. The web interface provides the environment within which the user performs these tasks. The website features such as navigation; aesthetic; connectivity and others could be equal to those website hygiene features whose presence in a website is likely to add to user satisfaction but are not sufficient to guarantee user satisfaction (Zhang et al., 2000). For instance, a website having quick loading time or easy navigation does not guarantee that the users will be satisfied while using it. Although these can add to the overall user satisfaction, user satisfaction can only be achieved when the content of the website meets the needs and aspirations of the users.

One of the main goals of website designers is to achieve user satisfaction. When users are satisfied, it is expected that they may revisit the website later and recommend it to others. In the context of the public sector website, the user satisfaction can be determined through the quality of the service received through the website. Thus, in this context, the intrinsic factors that drive overall user satisfaction are those factors that relate to the service dimensions while the extrinsic factors are those relate to the website design. For example, a website may have a good loading time; good aesthetic; and sound external links; however, a user may not get the optimal satisfaction from the service offered. Therefore, the present study integrated the service quality model into the Herzberg's Theory to investigate website quality from the user satisfaction through the service quality perspective. The next section presents a discussion on the model proposed in the current study.

\section{Public Agency Website Quality Assessment Model (PWebQAM)}

The proposed model is based on the e-CiRM model proposed by (Zaman, 2010), SERVEQUAL model of (Parasuraman et al., 2005) and Herzberg's Theory. Figure 1 shows the conceptual framework for public agency websites quality assessment. The framework comprises three constructs, namely: Perceived Websites Quality (PWQ), Perceived Service Quality (PSQ) and User Satisfaction (US). PWQ served as the independent variable and was measured by seven (7) indicators (navigation, e-service, aesthetic, transparency, site credibility, connectedness and interaction). Considering the WQ and PSQ, PSQ served as dependent variables whereas for the PWQ and US, US served as the dependent variable in the model. In addition, considering the whole three constructs together, US depend on both PWQ and PSQ. Based on the literature review presented, hypotheses were formulated.

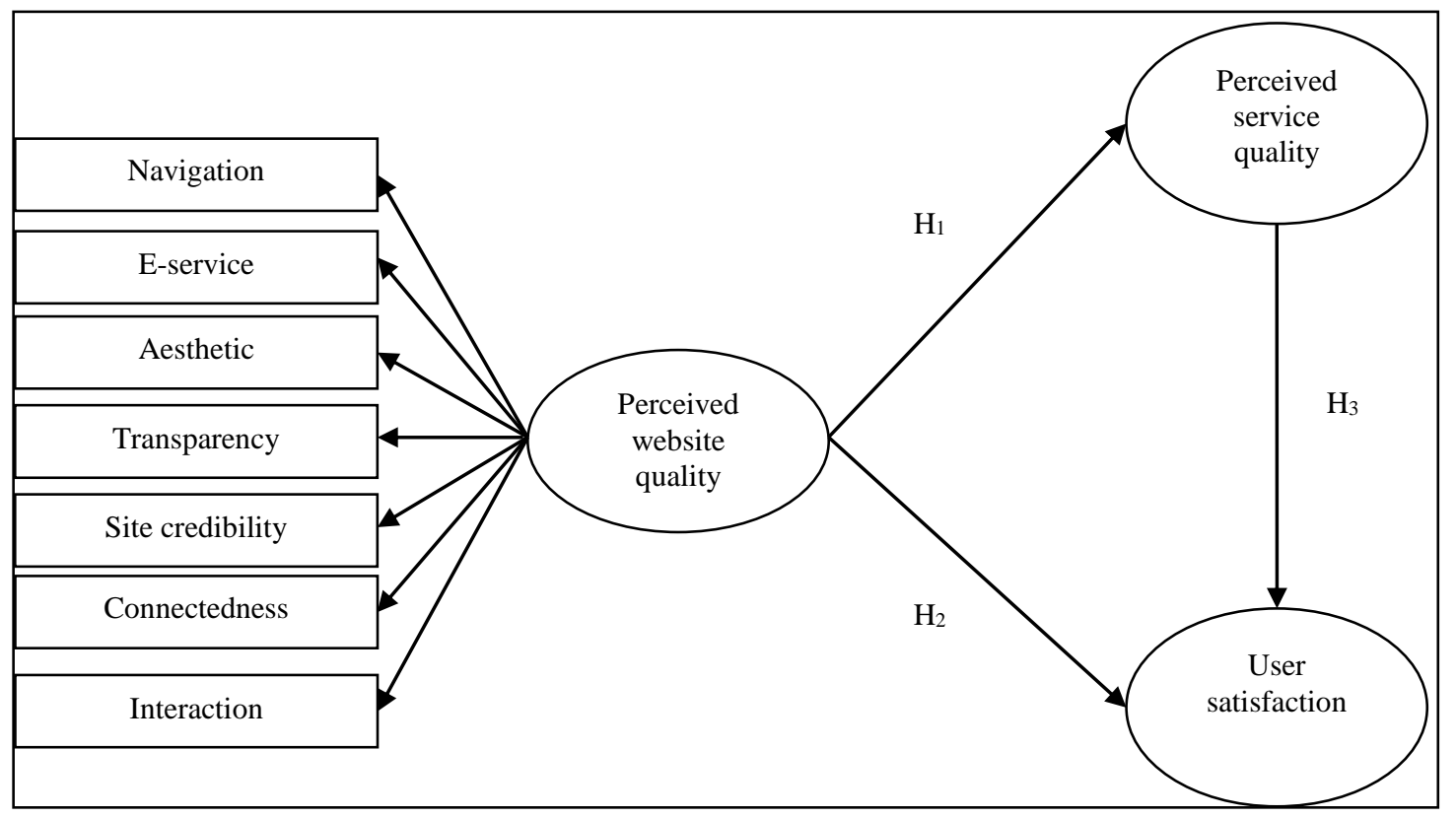

Fig. 1: Research model (PWebQAM) 


\section{Service Quality and Website Quality}

In the context of internet service, (Palmer, 2002) described service quality as overall customer assessment and judgement about the service provided through website. Zeithaml (2002) argued that in order to improve users' patronage of websites and establish user loyalty, organisations have to change their focus from the aspect of exchange and transactions to the aspect of service quality. Previous studies conducted in the e-commerce subsector revealed that service quality plays a significant role in influencing the decision of website users. For instance, in e-business context, (Chang and Chen, 2008) found that users' perception of website quality positively impact on their revisit and subsequent purchase decision. Therefore, with respect to the current study it was hypothesised that:

H1: Perceived website quality has significant, positive effect on perceived service quality.

\section{User Satisfaction and Website Quality}

User satisfaction is the extent to which a user's perception of the service confirms his or her expectations. By implication, high degree of satisfaction is achieved when the user's expectations are met and vice-versa. Many studies have established a positive relationship between online user satisfaction and patronage of organisations' websites, especially in the e-commerce context. For instance, (DeLone and McLean, 2003) found that website quality dimensions have significant effect on user satisfaction. Zaidi (2017) investigated citizen's satisfaction with e-government services and found that website quality dimensions have significant influence on user overall satisfaction. Therefore, in the context of this study it was hypothesised that:

\section{H2: Perceived website quality has significant, positive effect on user satisfaction}

\section{Perceived Service Quality and user Satisfaction}

Devaraj et al. (2002) defined satisfaction as the summary of psychological state and effective response to the overall online information seeking experience. High service quality encourages website users to form a positive attitude towards a website which increases satisfaction and trust (Chen and Teng, 2013). Similarly, (Petter et al., 2012) asserted that users' perception of website service quality have a positive effect on satisfaction. Thus, it was hypothesised that:

H3: Perceived service quality has significant, positive effect on user satisfaction.

\section{Methodology}

The study used a quantitative research design where questionnaire was administered to a total of 250 respondents out of which 185 valid questionnaires were used for the analysis. The questionnaire was designed in a 5-point Likert-scale format. A convenience sampling technique was used to administer the questionnaire to the respondents consisted of users of NMC in the UAE. Data analysis was conducted using the Partial Least Squares Structural Equation Modelling software (SmartPLS 3.2.8). The PLS-SEM analysis followed the two-stage procedure that involved measurement model evaluation and structural model evaluation as recommended in (Hair Jr. et al., 2016). The hypotheses were tested by testing the path coefficients of the structural model for significance at $95 \%$ confidence interval.

\section{Results}

\section{Measurement Model Assessment}

Figure 2 presents the measurement model of the conceptual framework developed for the study. The model consisted of three constructs Website Quality (PWQ), Service Quality (PSQ) and User Satisfaction (US). Both PWQ and PSQ were measured by five dimensions where each dimension was further measured by indicators. User satisfaction on the other hand was measured by five indicators. The dimensions of the PWQ are navigation, e-service, aesthetic, transparency, site credibility, connectedness and interaction. From Fig. 2 , it is clearly shown that among the initial seven dimensions that were originally conceptualised to constitute the PWQ only five are retained. This arises from the fact that the indicator loadings of connectedness and interaction in the first round of analysis were low which affected the Average Variance Extracted (AVE) of the construct. The two dimensions were removed in subsequent analysis in order to improve the AVE (Hair Jr. et al., 2016).

The indicator loading measure the strength and direction of the relationship between indicator and the latent construct. It measures the absolute importance of an indicator in forming the latent construct (Hair Jr. et al., 2016). This implies that indicator loadings with high value contribute more than indicators with lower loadings in defining the construct. As shown in Fig. 2, the indicator loading of aesthetic in the PWQ construct, has the highest loading $(\mathrm{r}=0.872 ; \mathrm{p}<0.05)$. The next dimension with highest indicator loading in descending order are: E-service $(\mathrm{r}=0.841 ; \mathrm{p}<0.05)$; navigation loading $(r=0.799 ; p<0.05)$; site credibility loading $(r=$ $0.519 ; \mathrm{p}<0.05)$ and transparency loading $(r=0.570$; $\mathrm{p}<0.05)$. This suggests that, users of NMC websites considered these dimensions as the most important determinants of website quality. 


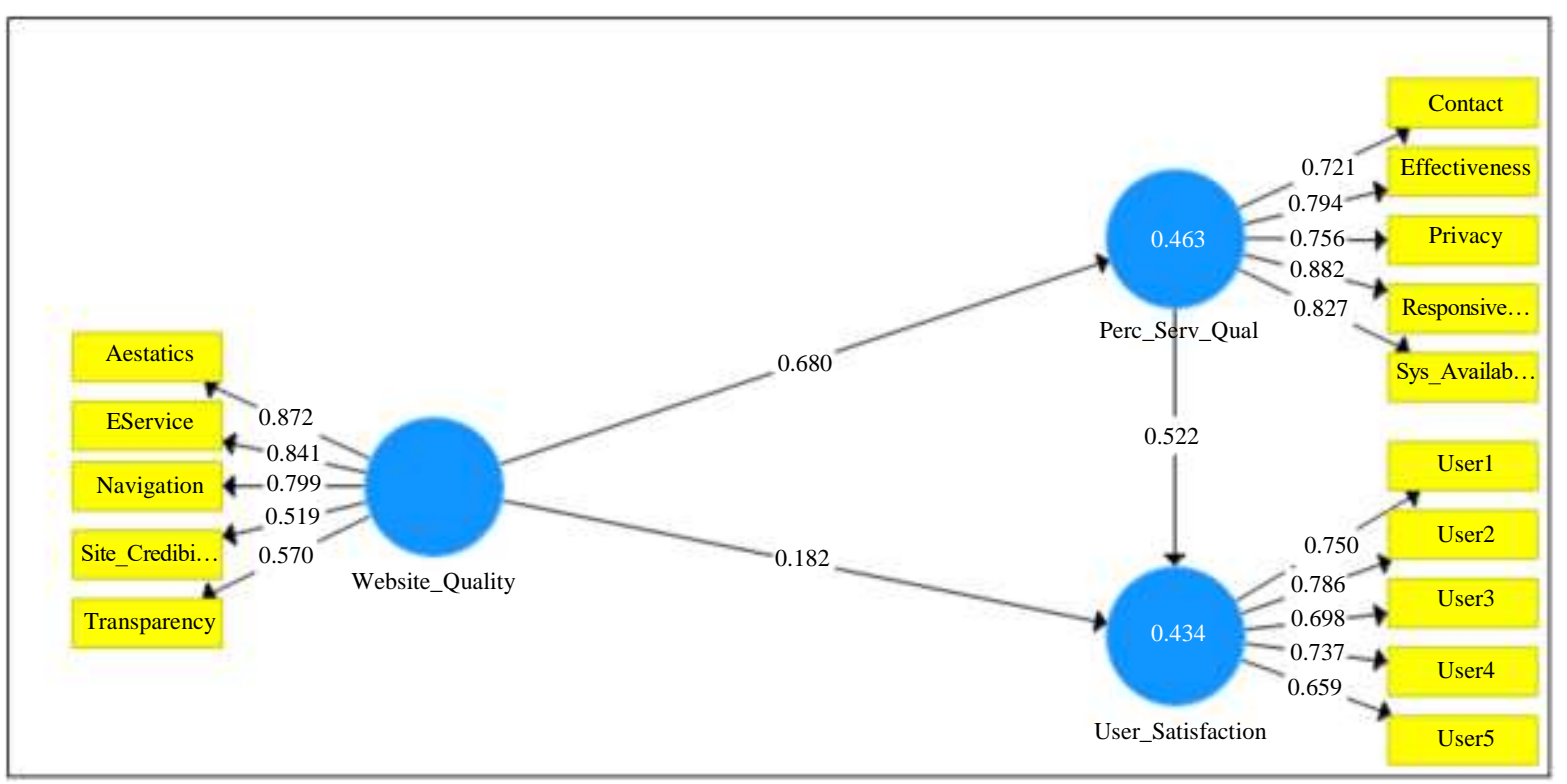

Fig. 2: Measurement model for website quality framework

The PSQ constructs has five dimensions as indicated in Fig. 2. The indicator loadings of the dimensions on the construct shows that responsiveness is the most influential dimension $(\mathrm{r}=$ $0.882 ; \mathrm{p}<0.05)$ followed by system availability ( $\mathrm{r}=$ $0.827 ; \mathrm{p}<0.05)$, effectiveness $(\mathrm{r}=0.794 ; \mathrm{p}<0.05)$, privacy $(r=0.756 ; \mathrm{p}<0.05)$ and contact $(\mathrm{r}=0.721$; $\mathrm{p}<0.05)$ in descending order of importance.

For user satisfaction construct, five indicators are shown to represent the construct. The most important indicator based on indicator loading is user2 (the service provided by NMC through its website is effective and efficient $)(r=0.786 ; \mathrm{p}<0.05)$. This is followed by the indicator user1 which states that "I am satisfied with the short response time for general inquiries" ( $\mathrm{r}=0.750 ; \mathrm{p}<0.05)$; user4 "The service provided by NMC through its website is satisfactory and full of confidentiality" $(r=0.737$; $\mathrm{p}<0.05)$; user3 "The service provided by NMC through its website is valuable" ( $\mathrm{r}=0.698 ; \mathrm{p}<0.05)$ and lastly user5 "I am fully satisfied with the services provided by NMC through its website" ( $r=0.659 ; \mathrm{p}<0.05)$.

As shown in Fig. 2 the relationship between the constructs and their respective indicators is reflective. This implies that to test the validity of the model, the indicator loadings, Average Variance Extracted (AVE), composite reliability and discriminant validity must be computed (Hair et al., 2011). All these parameters were assessed in the measurement model assessment stage. Henseler et al. (2015) stated that before evaluating the structural model for goodness-of-fit, measurement model has to be assessed. The main purpose of assessing the measurement model is to ensure that construct validity is achieved (Mohammed and Sulaiman, 2018). Hair Jr. et al. (2016) defined construct validity as the extent to which the indicators of a construct represent the underlying latent variable. Convergent validity and discriminant validity are the two main measures of construct validity. While convergent validity measures the degree of correlation between the indicators of a latent construct, discriminant validity measures the uniqueness of each construct in relation to other constructs in the model (Hair Jr. et al., 2016).

\section{Convergent Validity}

Hair et al. (2014) defined convergent validity as the extent to which the indicators of a latent construct correlate. To measure convergent validity of a measurement model, the indicator loading (outer loading) and the AVE are used as criteria (Hair et al., 2011). Indicator reliability is the measure of the absolute importance of individual indicator (measurement item) in defining the latent construct. It shows the relationship between the latent construct and the measurement items (Hair et al., 2014). Becker et al. (2012) recommended that the outer loading of the measurement item should be above 0.70. However, (Hair et al., 2014) argued those values less than 0.70 are also acceptable provided that the AVE is achieved. Another measure of convergent validity is the AVE. Hair et al. (2014) described it as the overall mean value of the squared loadings of the indicators of a latent construct. According to (Fornell and Larcker, 1981), the AVE measures the amount of variance a latent construct explained from its measurement items in relation to the amount explained by measurement error. Hair et al. (2014) recommended that AVE should be 
0.50 and above which indicates that at least more than half of the variance in the indicator is explained by the construct. Another measure of construct validity is composite reliability. The composite reliability is a measure of internal consistency. It measures the degree of inter-correlation among indicators of a latent construct (Hair et al., 2014). The criterion for testing composite reliability is for the index to be above 0.70 even though 0.60 is also acceptable in exploratory research (Hair et al., 2011).
Table 1 shows the convergent validity of the research constructs indicated by the outer loading of the indicators, AVE and Composite Reliability (CR) of the measurement model. As shown in the table, all the parameters met the recommended thresholds for model's convergent validity. Specifically, the outer loadings ranged from 0.52 to 0.88 and they were all statistically significant. Similarly, the AVEs reported values within the acceptable threshold of 0.50 whereas CRs were greater than 0.70 .

Table 1: Convergent validity of the research constructs

\begin{tabular}{|c|c|c|c|c|c|c|}
\hline Constructs & Items & Outer loading & T Statistics & P-Values & AVE & $\mathrm{CR}$ \\
\hline \multirow[t]{5}{*}{ Perceived website quality } & Aesthetics & 0.87 & 49.22 & 0.00 & & \\
\hline & EService & 0.84 & 40.71 & 0.00 & & \\
\hline & Navigation & 0.80 & 24.84 & 0.00 & 0.54 & 0.85 \\
\hline & Site credibility & 0.52 & 7.13 & 0.00 & & \\
\hline & Transparency & 0.57 & 7.58 & 0.00 & & \\
\hline \multirow[t]{5}{*}{ Perceived service quality } & Contact & 0.72 & 18.47 & 0.00 & & \\
\hline & Effectiveness & 0.79 & 28.03 & 0.00 & 0.64 & 0.90 \\
\hline & Privacy & 0.76 & 16.97 & 0.00 & & \\
\hline & Responsiveness & 0.88 & 48.04 & 0.00 & & \\
\hline & System availability & 0.83 & 28.79 & 0.00 & & \\
\hline \multirow[t]{5}{*}{ User satisfaction } & user1 & 0.75 & 20.36 & 0.00 & & \\
\hline & user2 & 0.79 & 25.68 & 0.00 & 0.53 & 0.85 \\
\hline & user3 & 0.70 & 14.16 & 0.00 & & \\
\hline & user4 & 0.74 & 15.70 & 0.00 & & \\
\hline & user5 & 0.66 & 12.25 & 0.00 & & \\
\hline
\end{tabular}

Table 2: Heterotrait-Monotrait ratio (HTMT)

\begin{tabular}{llll}
\hline & Perceived service quality & User satisfaction & Website quality \\
\hline Perceived service quality & & & \\
User satisfaction & 0.78 & 0.61 & \\
Website quality & 0.75 & 0.75 & \\
\hline
\end{tabular}

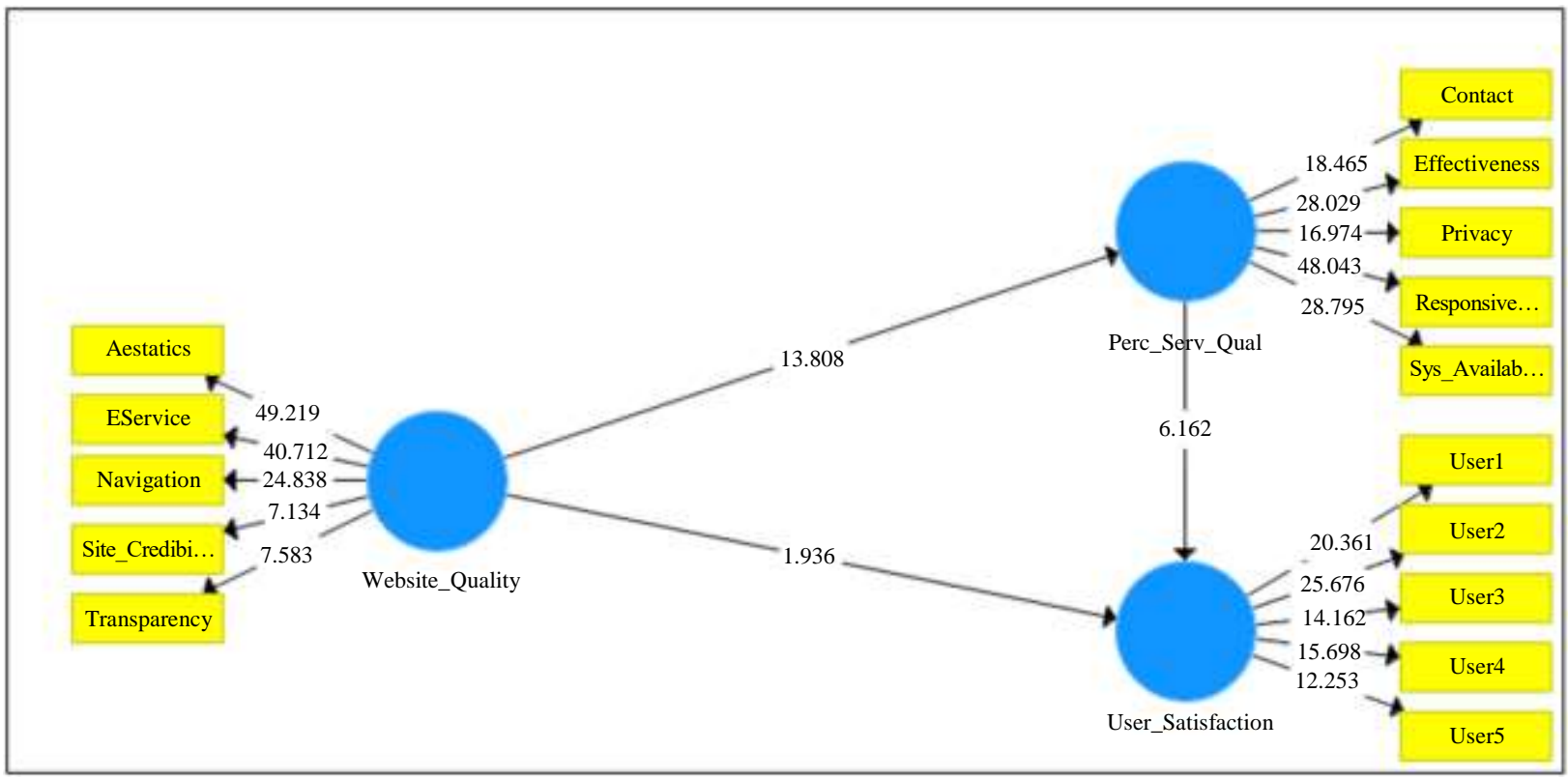

Fig. 3: Structural model for website quality framework 


\section{Discriminant Validity}

Upon establishing composite reliability, the discriminant validity was further reported. It is a measure of the uniqueness of latent construct with respect to other constructs in the model. Henseler et al. (2015) recommended that discriminant validity is assessed using Hetrotrait_Monotrait (HTMT) criterion. The HTMT criterion is a recently recommended way of assessing discriminant validity. Henseler et al. (2015) described it as the most conservative method in assessing discriminant validity. To achieve discriminant validity, the correlations among latent constructs should fall between 0.85 and 0.90 . Thus, any correlation between two latent construct that exceeds this limit indicates that discriminant validity assumptions is violated. Table 2 shows the results of the HTMT. The results showed that all the correlations among the constructs in the model were within the acceptable limit of $\left(r<\right.$ HTMT $\left._{.85}\right)$ as recommended by a study (Henseler et al., 2015).

Structural model evaluation and hypotheses testing

The structural model evaluation involves collinearity assessment, testing of significance of the path relationships, $\mathrm{R}^{2}$ assessment and effect size assessment (Hair et al., 2014). Figure 3 shows the structural model extracted from the PLS software.

Collinearity measures the degree of correlation among the independent variables in a model. In conducting a multivariate analysis, assessment of collinearity is very important. Ensuring absence or minimal collinearity leads to an unbiased estimation of path coefficient. Collinearity is assessed by examining the Variance Inflation Factor (VIF) across the exogenous constructs in the model. A threshold of 5 and above indicates the presence of collinearity whereas values less than 5 indicate that collinearity is not a severe problem (Hair et al., 2011; 2014). Table 3 shows the results of the collinearity test among the independent variables in the model. As shown in the table, the reported values were less than the threshold of 5, thus, indicating that there was a minimal case of collinearity in the data.

The path coefficient is the estimate of the hypothesized relationships among the model's constructs. According to (Hair et al., 2010), the path coefficient ranges from +1 to -1 where values tending towards 1 indicate a stronger relationship. Apart from the magnitude of the path coefficient, it is equally important for the estimates to be statistically significant. Table 4 presents the path coefficients for the relationships among the three constructs in the model. All the reported path coefficients were positive, indicating that the variables in the model are positively related. Table 3 shows the path coefficients of the relationship between the constructs in the model. The highest path coefficient was the Website Quality -> Perceived Service Quality $(\beta=0.68, \mathrm{t}=13.81, \mathrm{p}=$ $0.000)$ whereas the lowest coefficient was Website Quality $\rightarrow$ User Satisfaction $(\beta=0.18, t=1.94, p=$ 0.05 ). The path coefficients were used in testing the hypotheses. As shown in Table 4 all the three hypotheses were supported.

The third stage in the evaluation of the structural model in the PLS-SEM technique is to assess the overall model performance. This is indicated by the $\mathrm{R}^{2}$ value. According to (Mohammed and Sulaiman, 2018) the $\mathrm{R}^{2}$ is considered the overall measure of model performance. It is an indicator of the combined effects of all the independent variables in explaining the variation in the dependent variable in a model. Hair et al. (2014) provided a threshold for interpreting the $\mathrm{R}^{2}$ value where $\mathrm{R}^{2}$ of $0.75,0.50$ and 0.25 are considered to be of substantial, moderate and weak effect respectively. However, in behavioural research, consumer satisfaction studies and other related areas in management and social science fields, $\mathrm{R}^{2}$ value of 0.20 are considered of high effect (Hair et al., 2014). Figure 2 that displays measurement model for website quality framework where the $\mathrm{R}^{2}$ value of the model is shown. It is shown that Website Quality explained about $46 \%$ of Service Quality whereas about $43 \%$ of the variation in User satisfaction was jointly explained by Website Quality and Service Quality.

The effect size measures the relative importance of individual construct or variable in the overall performance of the model (Hair Jr. et al., 2016). It indicates the change in $\mathrm{R}^{2}$ resulted from the removal of one of the independent variables in a model. The (Cohen, 1992) guideline was used to assess the relative importance of an exogenous construct where $f^{2}$ values of $0.02,0.15$ and 0.35 are considered small, medium and large respectively. Table 3 shows the effect sizes of the exogenous constructs in the model. The result showed that Website Quality had large effect size on $\mathrm{R}^{2}$ in the relationship between PWQ and PSQ $\left(f^{2}=0.86 ; \mathrm{t}=3.42\right.$; $\mathrm{p}=0.000$ ). However, in the relationship between PWQ and User Satisfaction, PWQ had small effect $\left(f^{2}=0.03\right.$; $=0.83 ; \mathrm{p}=0.41)$ on $\mathrm{R}^{2}$ while PSQ had medium effect $\left(f^{2}\right.$ $=0.26 ; \mathrm{t}=2.73 ; \mathrm{p}=0.001$ ).

Table 3: Collinearity test

\begin{tabular}{llc}
\hline & Perceived service quality & User satisfaction \\
\hline $\begin{array}{l}\text { Perceived service quality } \\
\text { User satisfaction }\end{array}$ & & 1.86 \\
Website quality & 1.00 & 1.86 \\
\hline
\end{tabular}


Table 4: Hypotheses testing

\begin{tabular}{llrlll}
\hline & Path coefficient & t-value & p-value & $f^{2}$ & Decision \\
\hline Perceived service quality -> User satisfaction & 0.52 & 6.16 & 0.00 & 0.26 & Supported \\
Website quality $\rightarrow$ Perceived service quality & 0.68 & 13.81 & 0.00 & 0.86 & Supported \\
Website quality $\rightarrow$ User satisfaction & 0.18 & 1.94 & 0.05 & 0.03 & Supported \\
\hline
\end{tabular}

\section{Discussion}

The proposed framework measures website quality from service quality and user satisfaction perspectives. The initial conceptualization of the website quality constructs comprises seven dimensions (navigation, eservice, aesthetic, transparency, site credibility, connectedness and interaction). After the analysis, only five dimensions are retained. The relationship between the five dimensions (aesthetic, e-service, navigation, site credibility and transparency) and the website quality constructs are all strong and statistically significant. The findings show that website quality has a strong and significant effect on perceived service quality. This finding confirms the findings of (Ahmad et al., 2016) where the website quality affects website visitors' perception of service quality in the e-commerce setting. Similarly, the findings agree with the findings of (Khalil, 2017) who found that website quality influences users' perception of service quality offered by an organization. This suggests that users of public sector agencies' website gauge website quality on the quality of service they receive through browsing the site. Similar conclusion is reached by (Zaman, 2010) where users of public sector website often rate the performance of the website based on their perception of the service offered.

Furthermore, another finding of the study reveals that website quality has a significant effect on users' satisfaction. The finding confirms that of (Zaman's, 2010) study which discovered a significant positive effect between website quality and users' satisfaction in public sector website. This implies that high quality website is expected to increase service satisfaction. This has been largely reported in studies within the e-commerce context. For instance, (Weber and Badenhorst-Weiss, 2018; Chen and Teng, 2013; Petter et al., 2012; Jeon, 2009) report that website quality affects online shoppers' satisfaction.

Another important relationship that is evaluated in the research framework is the effect of perceived service quality on users' satisfaction. As evidenced in previous studies notably, (Petter et al., 2012; Saha et al., 2012; Zeithaml, 2002; Montoya-Weiss et al., 2003), the quality of service offered through website or e-service channels has a direct effect on users' satisfaction. With regard to public sector website, previous studies identified assurance and reliability components of service quality as important predictors of users' continued use of government e-service (Qadar et al., 2016). In the context of the present study, system availability and responsiveness are found to be very important measures of service quality. This implies that the reliability of the service received by users and the timely response to their complaints and request through the website are important determinants of their satisfaction with the overall website. Thus, the proposed framework establishes that NMC website users evaluate the quality of the website and its content based on the perception of the quality of the services received through the website which translates into their satisfaction.

\section{Conclusion}

The study evaluates website quality of a public agency website from the perspective of users using SERVQUAL and Herzberg's Two Factor models. A new framework based on the SERVQUAL and Herzberg's Two Factor theory is proposed for measuring website quality in a typical government agency, hence achieving the research goal. Theoretically, the study contributes by integrating the service quality model into the Herzberg's Theory in order to investigate website quality from the users' perspective through the service quality perspective which results in the proposed Public Agency Website Quality Assessment Model (PWebQAM). The result reveals that website quality has a statistically significant effect on user satisfaction and perceived service quality. On the practical perspective, the proposed framework (PWebQAM) is expected to provide NMC with information about the key aspect of its website that the website users considered important determinants of service quality and user satisfaction. This is expected to provide the agency with a tool to improve their services so that it can provide quality content that fulfil users' satisfaction.

\section{Author's Contributions}

Mohammed Albalushi: Participated in all experiments, coordinated the data-analysis and contributed to the writing of manuscript.

Zanariah Jano: Supervising, directing and suggesting research details, designed the research plan and organized the study.

Indra Devi: Analyze the research and review all inputs and suggest necessary adjustments.

\section{Ethics}

This article is original and contains unpublished material. The corresponding author confirms that all of the other authors have read and approved the manuscript and no ethical issues involved. 


\section{References}

Abdallah, S. \& Jaleel, B. (2015) Website appeal: development of an assessment tool and evaluation framework of e-marketing, Journal of theoretical and applied electronic commerce research, 10(3), 45-62.

Ahmad, A., Rahman, O., \& Khan, M. N. (2016). Consumer's perception of website service quality: An empirical study. Journal of Internet Commerce, 15(2), 125-141.

Aladwani, A. M. (2013). A cross-cultural comparison of Kuwaiti and British citizens' views of eGovernment interface quality. Government Information Quarterly, 30(1), 74-86.

Aladwani, A. M. (2014). Cognitive beliefs about and the positive psychological tendency towards eGovernment quality. Procedia - Social and Behavioral Sciences, 127, 570-574.

Aladwani, A. M. (2017). Compatible quality of social media content: Conceptualization, measurement and affordances. International Journal of Information Management, 37(6), 576-582.

Aladwani, A. M., \& Palvia, P. C. (2002). Developing and validating an instrument for measuring userperceived web quality. Information \& management, 39(6), 467-476.

Aral, S., \& Walker, D. (2011). Creating social contagion through viral product design: A randomized trial of peer influence in networks. Management science, 57(9), 1623-1639.

Aral, S., Dellarocas, C., \& Godes, D. (2013). Introduction to the special issue-social media and business transformation: a framework for research. Information Systems Research, 24(1), 3-13.

Asadi, N., \& Lin, J. (2013). Fast candidate generation for real-time tweet search with bloom filter chains. ACM Transactions on Information Systems (TOIS), 31(3), 1-36.

Awamleh, R., \& Fernandes, C. (2005). Internet banking: an empirical investigation into the extent of adoption by banks and the determinants of customer satisfaction in the United Arab Emirates.

Bagozzi, R.P. (1980). Causal Models in Marketing. New York: John Wiley.

Bagozzi, R.P., \& Phillips, L.W. (1982). Representing and testing organizational theories: A holistic construal. Administrative Science Quarterly, 27(3) 459-489.

Bai, B., Law, R., \& Wen, I. (2008). The impact of website quality on customer satisfaction and purchase intentions: Evidence from Chinese online visitors. International journal of hospitality management, 27(3), 391-402.
Becker, J., Klein, K., \& Wetzels, M. (2012). Hierarchical Latent Variable Models in PLS-SEM: Guidelines for Using Reflective-Formative Type Models. Long Range Planning, 45(5-6), 359-394.

Boldi, P., Bonchi, F., Castillo, C., \& Vigna, S. (2011). Viscous democracy for social networks. Communications of the ACM, 54(6), 129-137.

Brewer, G. A., Neubauer, B. J., \& Geiselhart, K. 2006. Designing and implementing e-government systems. Critical implications for public administration and democracy. Administration \& Society, 38(4): 472-499.

Chang, H. H., \& Chen, S. W. (2008). The impact of online store environment cues on purchase intention. Online information review.

Chang, K. C., Kuo, N. T., Hsu, C. L., \& Cheng, Y. S. (2014). The impact of website quality and perceived trust on customer purchase intention in the hotel sector: website brand and perceived value as moderators. International Journal of Innovation, Management and Technology, 5(4), 255.

Chen, M. Y., \& Teng, C. I. (2013). A comprehensive model of the effects of online store image on purchase intention in an e-commerce environment. Electronic Commerce Research, 13(1), 1-23.

Cohen, J. (1992). A power primer. Psychological bulletin, 112(1), 155.

Crandall, D., \& Snavely, N. (2012). Modeling people and places with internet photo collections. Communications of the ACM, 55(6), 52-60.

Dang, Y., Zhang, Y., Hu, P. J. H., Brown, S. A., Ku, Y., Wang, J. H., et al. (2014). An integrated framework for analyzing multilingual content in Web 2.0 social media. Decision Support Systems, 61(1), 126-135.

DeLone, W. H., \& McLean, E. R. (2003). The DeLone and McLean model of information systems success: A ten-year update. Journal of Management Information Systems, 19(4), 9-30.

Devaraj, S., Fan, M., \& Kohli, R. (2002). Antecedents of B2C channel satisfaction and preference: validating e-commerce metrics. Information systems research, 13 (3), 316-333.

Díaz, J., Rusu, C., \& Collazos, C. A. (2017). Experimental validation of a set of cultural-oriented usability heuristics: e-Commerce websites evaluation. Computer Standards \& Interfaces, 50, 160-178.

Fornell, C., \& Larcker, D. F. (1981). Evaluating structural equation models with unobservable variables and measurement error. Journal of marketing research, 18(1), 39-50.

Hair, J., Black, W., Babin, B., \& Anderson, R. (2010). Multivariate data analysis 7 th edth ed. 
Hair, J. F., Ringle, C. M., \& Sarstedt, M. (2011). PLSSEM: Indeed a silver bullet. Journal of Marketing theory and Practice, 19(2), 139-152.

Hair, J. F., Hult, G. T. M., Ringle, C. M., \& Sarstedt, M. (2014). A primer on partial least squares structural equation modeling (PLS-SEM). Thousand Oaks, Califonia: Sage Publications.

Hair Jr, J. F., Sarstedt, M., Matthews, L. M., \& Ringle, C. M. (2016). Identifying and treating unobserved heterogeneity with FIMIX-PLS: part I-method. European Business Review.

Hargittai, E. (2007). A framework for studying differences in people's digital media uses. In Grenzenlose Cyberwelt? (pp. 121-136). VS Verlag für Sozialwissenschaften.

Hasan, L., \& Abuelrub, E. (2011). Assessing the quality of web sites. Applied Computing and Informatics, 9(1), 11-29.

Hearst, M. (2011). 'Natural' search user interfaces. Communications of the ACM, 54(11), 60-67.

Henseler, J., Ringle, C. M., \& Sarstedt, M. (2015). A new criterion for assessing discriminant validity in variance-based structural equation modeling. Journal of the academy of marketing science, 43(1), 115-135.

Herzberg, F. (1968). One more time: How do you motivate employees.

ITU. (2016). Measuring the Information Society Report 2016. Geneva: International Telecommunication Union.

Jeon, M. M. (2009). Impact of perceived website service quality on customer e-loyalty on a lodging website. Iowa State University.

Jiang, Z., Wang, W., Tan, B. C., \& Yu, J. (2016). The determinants and impacts of aesthetics in users' first interaction with websites. Journal of Management Information Systems, 33(1), 229-259.

Jin, C. (2013). The perspective of a revised TRAM on social capital building: The case of Facebook usage. Information \& Management, 50(4), 162-168.

Khalil, H. (2017). The Role of the Quality of a Website in Consumer Perception.

Kim, C., \& Kim, D. J. (2017). Uncovering the value stream of digital content business from users' viewpoint. International Journal of Information Management, 37(6), 553-565.

Loiacono, E. T., Watson, R. T., \& Goodhue, D. L. (2002). WebQual: A measure of website quality. Marketing theory and applications, 13(3), 432-438.

Maulana, A. E., \& Cai, T. (2011). An investigation into the determinant of Corporate Blog Connectedness.

Mebrate, T. (2010). A framework for evaluating academic website's quality from students' perspective.
Mohammed, M. I., \& Sulaiman, N. (2018). Determinants of Reverse Mortgage Usage in Malaysia. Real Estate Management and Valuation, 26(3), 5-23.

Montoya-Weiss, M. M., Voss, G. B., \& Grewal, D. (2003). Determinants of online channel use and overall satisfaction with a relational, multichannel service provider. Journal of the Academy of Marketing Science, 31(4), 448-458.

Mueller, J. D., \& Mack R. (2003) Website atmospherics: Motivators or hygiene factors? Journal of Business \& Economics Research, 1(6), 73-82.

Palmer, J. W. (2002). Web site usability, design and performance metrics. Information systems research, 13(2), 151-167.

Parasuraman, A., Zeithaml, V. A., \& Malhotra, A. (2005). ES-QUAL: A multiple-item scale for assessing electronic service quality. Journal of service research, 7(3), 213-233.

Petter, S., DeLone, W., \& McLean, E. R. (2012). The past, present and future of "IS success". Journal of the Association for Information Systems, 13(5), 2.

Phang, C. W., Zhang, C., \& Sutanto, J. (2013). The influence of user interaction and participation in social media on the consumption intention of niche products. Information \& Management, 50(8), 661-672.

Qadar, S., Moazzam, A., \& Ansari, N. (2016). E-Tax Website Quality: An Evaluation Framework. Pakistan Journal of Information Management and Libraries, 16.

Ritonummi, S. (2020). User experience on an ecommerce website: a case study.

Ryan, S. D. (2010). Information systems and healthcare XXXVI: Building and maintaining social capitalevidence from the field. Communications of the Association for Information Systems, 27(1), 18.

Saha, P., Nath, A. K., \& Salehi-Sangari, E. (2012). Evaluation of government e-tax websites: an information quality and system quality approach. Transforming Government: People, Process and Policy, 6 (3), 300321.

Sakaki, T., Okazaki, M., \& Matsuo, Y. (2012). Tweet analysis for real-time event detection and earthquake reporting system development. IEEE Transactions on Knowledge and Data Engineering, 25(4), 919-931.

Stanujkic, D., Smarandache, F., Zavadskas, E. K., \& Karabasevic, D. (2018). An Approach to Measuring the Website Quality Based on Neutrosophic Sets. Infinite Study.

Strother, J. B., Fazal, Z., \& Millsap, M. (2009). Legal and ethical issues of the corporate blogosphere. IEEE transactions on professional communication, 52(3), 243-253. 
Vaknin, S. (2009). TrendSiters digital content and web technologies. Sam Vaknin's United Press International.

Verkijika, S. F., \& De Wet, L. (2018). Quality assessment of e-government websites in $\mathrm{S}$ ub-S aharan A frica: A public values perspective. The Electronic Journal of Information Systems in Developing Countries, 84(2), e12015.

Weber, A. N., \& Badenhorst-Weiss, J. A. (2018). The 'new'bricks-and-mortar store: An evaluation of website quality of online grocery retailers in BRICS countries. African Journal of Science, Technology, Innovation and Development, 10(1), 85-97.

Wolfinbarger, M., \& Gilly, M. C. (2003). eTailQ: dimensionalizing, measuring and predicting etail quality. Journal of retailing, 79(3), 183-198.

WEF. (2016). Digital media and society implications in a hyperconnected era. In Shaping the Future Implications of Digital Media for Society. World Economic Forum. https:/www.weforum.org/docs/WEFUSA_DigitaMe diaAndSociety_Report2016.pdf\&ved=2ahUKEwKx r7E6d7tAhVSTsAKHdksCuYQFjAAegQIAxAC\&u sg=AOvVaw1WnQo-8GTZydOH0DLpleCU

$\mathrm{Wu}$, L. (2013). Social network effects on productivity and job security: Evidence from the adoption of a social networking tool. Information Systems Research, 24(1), 30-51.
Zaidi, S. F. H. (2017). E-government services effectiveness evaluation framework (E-GEEF): a case study of Indian e-tax service (Doctoral dissertation, London Metropolitan University).

Zaman, M. (2010). Quality of public sector website and its impact on citizen involvement.

Zeithaml, V. A. (2002). Service excellence in electronic channels. Managing Service Quality: An International Journal.

Zhang, P., \& Von Dran, G. M. (2000). Satisfiers and dissatisfiers: A two-factor model for website design and evaluation. Journal of the American society for information science, 51(14), 1253-1268.

Zhang, X., Keeling, K. B., \& Pavur, R. J. (2000). Information quality of commercial web site home pages: an explorative analysis. Paper presented at the Proceedings of the twenty first international conference on Information systems table of contents, Queensland, Australia.

Zhao, J. (2016). The influence of perceived website quality on Chinese consumers' online purchase intentions: utilitarian and hedonic impacts. HKU Theses Online (HKUTO). 